\title{
Cisapride reduces neonatal postoperative ileus: randomised placebo controlled trial
}

\author{
A Lander, R Redkar, G Nicholls, A Lawson, S R Choudhury, J J Corkery, P Gornall,
} R G Buick, I W Booth

Department of

Paediatric Surgery

Children's Hospital

Birmingham

R Redkar

G Nicholls

A Lawson

S R Choudhury

J J Corkery

P Gornall

P G Buick

Institute of Child

Health,

University of

Birmingham

A Lander

I W Booth

Correspondence to: Mr Anthony Lander Department of Paediatric Surgery, Birmingham Children's Hospital, Ladywood Middleway, Ladywood, Birmingham B16 8ET

Email:101366.153@

compuserve.com

Accepted 18 March 1997

Table 1 Characteristics mean (SEM) of cisapride and placebo groups

\begin{tabular}{|c|c|c|}
\hline & $\begin{array}{l}\text { Rectal cisapride }(n=11) \\
1.4-2.3 \mathrm{mg} / \mathrm{kg} / \text { day }\end{array}$ & Rectal placebo $(n=12)$ \\
\hline Gestation (weeks) & $37(0.4)$ & $37(0.4)$ \\
\hline Birthweight $(\mathrm{kg})$ & $2.6(0.16)$ & $2.5(0.12)$ \\
\hline $\begin{array}{l}\text { Aspirate volume on the day preceding } \\
\text { treatment }(\mathrm{ml} / \mathrm{kg} / \text { day })\end{array}$ & $12(3.5)$ & $11(2.3)$ \\
\hline
\end{tabular}

nal surgery.

(Arch Dis Child 1997;77:F119-F122)

Keywords: cisapride; gastroschisis; postoperative ileus; prokinesis

Prolonged functional intestinal obstruction complicates the postoperative management of some neonates after the surgical correction of gastroschisis, intestinal atresias, and malrotation. Although parenteral nutrition has revolutionised the care of these children, the longer it is required the greater are the risks of cholestasis and sepsis. ${ }^{1}$ Furthermore, longer periods in hospital have financial and social implications. Postoperative ileus is often the major factor contributing to the length of hospital stay.

The prokinetic agent cisapride (Prepulsid; Janssen Pharmaceutical Ltd), a substituted piperidinyl benzamide, is believed to work by enhancing the release of acetylcholine from the myenteric (Auerbach's) plexus. This is based on experiments with tetrodotoxin, a nerve blocker, and the anticholinergic agent atropine, both of which prevent cisapride induced prokinesis. ${ }^{2}$ Cisapride is at least comparable with metoclopramide in reducing gastric to caecal transit times in adults ${ }^{3}$ and is effective in adults with normal intestines in the immediate postoperative period ${ }^{4}$ and at $48-72$ hours. $^{5}{ }^{6}$ Its effectiveness in neonates, however, has not been studied. Cisapride is more effective than metoclopramide in improving the oesophageal clearance of refluxed acid and in increasing lower oesophageal sphincter tone in gastrooesophageal reflux in infants. ${ }^{7}$ It decreases duodeno-gastric reflux ${ }^{8}$ and is used to treat delayed gastric emptying, particularly in diabetes. ${ }^{9}$ Cisapride also has a prokinetic action on the small and large intestine ${ }^{10}$ and has been used in idiopathic pseudo-obstruction, ${ }^{11}$ and in dysmotile neonatal small bowel. ${ }^{12}$ Cisapride does not have the antidopaminergic effects of extrapyramidal reactions and prolactin release which are seen with metoclopramide or domperidone.

We therefore wished to determine if there was measurable benefit from the use of cisapride in the management of prolonged postoperative neonatal ileus. $\mathrm{mg} / \mathrm{kg} /$ day); and neonates between $3.2-4.2 \mathrm{~kg}$ received one suppository every 12 hours (1.4$1.8 \mathrm{mg} / \mathrm{kg} /$ day). Cisapride and placebo suppositories were supplied by Janssen Pharmaceutical Ltd. As enteral feeds were progressively increased parenteral nutrition was decreased. Records of daily enteral intake, 


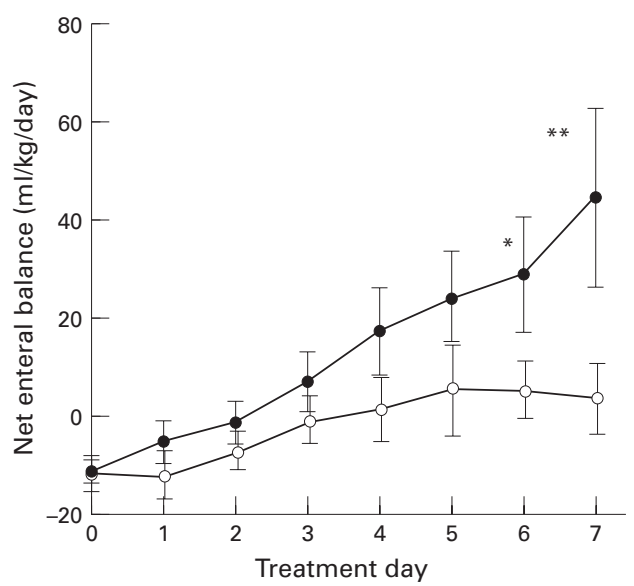

Figure 1 Graph of mean net enteral balance in $\mathrm{ml} / \mathrm{kg} /$ days for days 1-7 for cisapride $\bullet$ (1.4-2.3 $\mathrm{mg} / \mathrm{kg} /$ day $)(n=11)$ or placebo $\circ(n=12)$ in 23 neonates. Day 0 is the 10th postoperative day after abdominal surgery with persisting ileus. Error bars are standard errors. ${ }^{\star} P<0.04 ;{ }^{\star \star} P=0.02 ;$ t test.

total daily discarded nasogastric aspirates, and the passage of stool were prospectively recorded. A first sustained feed was defined as the first feed that led progressively to full enteral feeds. After seven days of treatment the trial was concluded and patients were managed as seen fit by their individual clinicians.

Statistical analysis was performed blind. Student's $t$ test was used to assess the difference in the means of normally distributed data.

\section{Results}

Thirty three neonates were entered into the study but 10 were withdrawn from analysis: four had not met the entry criteria as they received feeds on the tenth postoperative day; five patients completed the seven days of treatment but were subsequently found to be mechanically obstructed; and one receiving cisapride developed necrotising enterocolitis on treatment day 4 . Four of the five mechanical obstructions occurred at intestinal anastomoses, three were related to resected atresias in gastroschisis, and one to a resection for multiple small bowel atresias. One further patient who had had gastroschisis requiring a silo developed intestinal strictures.

Of the remaining 23 patients, 12 received placebo and 11 cisapride. Nineteen had had gastroschisis (all primarily closed), one patient receiving placebo had had duodenal stenosis and another had had multiple small bowel atresias; in each group there was one patient who had had jejunal atresia. The two groups were comparable for gestation, birthweight, and the volume of aspirates on the tenth post-

Table 2 Characteristics mean (SEM) of cisapride and placebo subgroups who attained a first sustained feed during treatment

\begin{tabular}{lll}
\hline & $\begin{array}{l}\text { Rectal cisapride }(n=8) \\
1.4-2.3 \mathrm{mg} / \mathrm{kg} / \text { day }\end{array}$ & Rectal placebo $(n=7)$ \\
\hline Gestation (weeks) & $37(0.4)$ & $37(0.3)$ \\
$\begin{array}{l}\text { Birthweight (kg) } \\
\begin{array}{l}\text { Aspirate volume on the day preceding } \\
\text { treatment (ml/kg/day) }\end{array}\end{array}$ & $2.66(0.22)$ & $2.58(0.16)$ \\
\hline
\end{tabular}

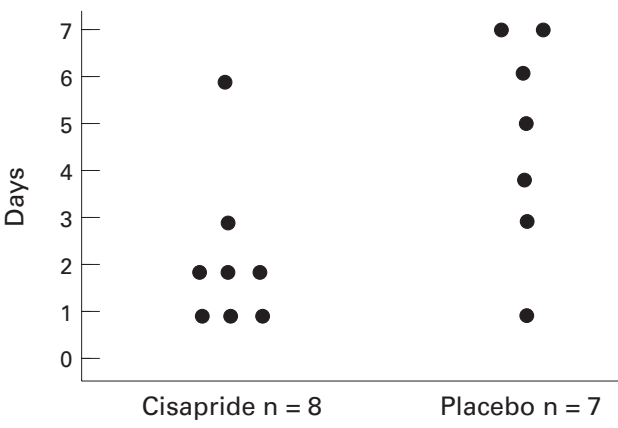

Figure 2 Scattergram of time from start of treatment to first sustained feed for neonates receiving rectal cisapride mean 2.3 days (SEM 0.6) and placebo mean 4.7 days (SEM 0.8) $P<0.029$; two tailed t test.

operative day (table 1). The mean aspirate volumes $/ \mathrm{kg}$ during the seven treatment days did not differ significantly. Both the daily and cumulative feed volumes $/ \mathrm{kg}$ and the number of days on which stools were passed were consistently better with cisapride. The net enteral balance $/ \mathrm{kg}$ was greater in the cisapride group than the placebo group, reaching significance at the $5 \%$ level on days 6 and 7 (fig 1).

Seven of $12(58 \%)$ patients receiving placebo and eight of $11(73 \%)$ receiving cisapride achieved a first sustained feed during the seven treatment days. Analysis of these subgroups showed that they were comparable with respect to gestation, birthweight, and the volume of aspirates on the 10th postoperative day (table $2)$. Five $(71 \%)$ of the placebo subgroup and five $(62 \%)$ of the cisapride subgroup received breast milk while the others received PeptiJunior (Cow and Gate). In both subgroups one neonate had jejunal atresia and in the placebo subgroup a further neonate had multiple small bowel atresias; the other 12 neonates had gastroschisis. The cisapride subgroup had a first sustained feed at a mean of 2.3 days (SEM $0.6)$; in the placebo subgroup the mean was 4.7 days (SEM 0.8) $(\mathrm{P}<0.029$ two tailed $t$ test) (fig 2). From the second treatment day the mean daily net enteral balance was positive and

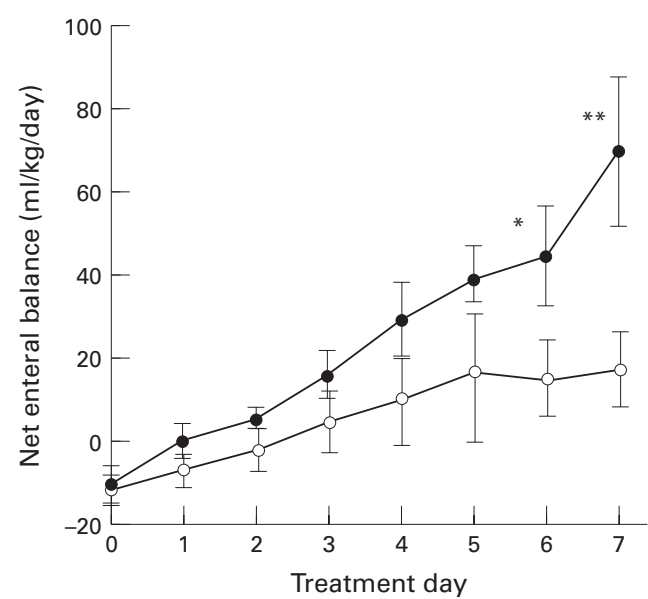

Figure 3 Graph of mean net enteral balance in $\mathrm{ml} / \mathrm{kg} /$ day for days 1-7 for neonates receiving cisapride $\bullet$ (1.4-2.3 $m g / k g /$ day $)(n=8)$ or placebo $\circ(n=7)$ in 15 neonates who attained a first sustained feed. Day 0 is the 10th postoperative day after abdominal surgery with persisting ileus. Error bars are standard errors. ${ }^{\star} P<0.04 ;{ }^{\star \star} P<$ 0.02; $t$ test. 


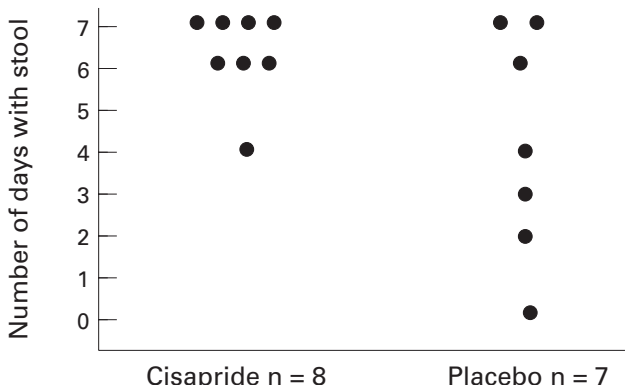

Figure 4 Scattergram of number of days on which stool was passed in neonates who attained a first sustained feed on rectal cisapride mean 6.3 days (SEM 0.4) and placebo mean 4.1 days (SEM 1.0); $P=0.059$, two tailed t test.

greatest in those receiving cisapride (fig 3), such that by the seventh treatment day it was 69 (SEM 18) $\mathrm{ml} / \mathrm{kg}$ for cisapride and 17 (SEM 8) $\mathrm{ml} / \mathrm{kg}$ for placebo $(\mathrm{P}<0.02 ; t$-test $)$. The average number of treatment days on which stool was passed was also greatest in the cisapride subgroup (6.3 (SEM 0.4) days) compared with placebo (4.1 (SEM 1.0) days) ( $\mathrm{P}=0.059$; two tailed $t$ test) (fig 4 ).

\section{Discussion}

We have shown that in postoperative neonatal ileus seven days of rectal cisapride (1.4-2.3 $\mathrm{mg} / \mathrm{kg} /$ day) started after the 10th postoperative day, increased the net enteral balance, decreased the time to the start of successful feeding, and decreased the number of days without stool.

The number of neonates enrolled in this study was small and the treatment period was brief. This precluded an analysis of the risks of hepatic dysfunction and the length of hospital stay. One neonate receiving cisapride developed necrotising enterocolitis and this has been reported as a possible serious adverse effect.

Importantly, the two subgroups were comparable for the number receiving breast milk which is known to promote faster gastric emptying than formula feeds. ${ }^{13}$ Furthermore, the neonate who had had multiple small bowel atresias and who received placebo did exceptionally well, having a net enteral balance of 64 $\mathrm{ml} / \mathrm{kg} /$ day by day 7 , and thus does not contribute to the poor performance of the placebo group. Indeed, if the analysis were limited to those with gastroschisis alone, the benefit of cisapride is more apparent. Although those in the cisapride group were discharged on average sooner than those in the placebo group, the observation is uninformative because at the end of the trial double blinded rectal medication was stopped. Some, but not all, patients in both groups then went on to receive oral cisapride.

Our series consisted, in the main, of patients with gastroschisis but included those with intestinal atresias. Some patients have a prolonged ileus after a Ladd's procedure for duodeno-jejunal malrotation. We have already shown that intestinal dysmotility is associated with operated malrotation, ${ }^{14}$ and we would expect such patients to respond to cisapride.

Only a few studies of prokinetic agents in neonates or infants have been carried out.
Erythromycin is prokinetic in the stomach and small bowel, acting through motilin receptors upstream of a cholinergic pathway, ${ }^{15}$ and in the ileum via a cholinergic and opiate independent calcium channel pathway, ${ }^{16}$ but no colonic effect has been shown. ${ }^{17}$ In adults erythromycin improves gastric emptying, ${ }^{18-19}$ decreases orocaecal transit times in diabetics,,$^{90}$ and has been used in pseudo-obstruction. ${ }^{21}$ In children, ${ }^{22}$ extremely low birthweight neonates, ${ }^{23}$ and premature neonates ${ }^{24}$ erythromycin may improve gastric emptying. Furthermore, erythromycin has been used successfully in postoperative intestinal dysmotility. ${ }^{25}$ However, these neonatal studies lacked adequate control groups. Erythromycin does not decrease the period of normal postoperative ileus in adults compared with placebo, ${ }^{26}$ but this brief ileus may well be somewhat different from the prolonged ileus of pseudo-obstruction or that seen in neonates after gastroschisis closure or the resection of intestinal atresias.

Metoclopramide doubles gastric emptying in infants with gastroparesis after abdominal surgery but is reported to have had no effect on seven premature neonates. ${ }^{27}$

There is growing evidence for an association between a lengthening of the electrocardiographic QT interval and high doses of cisapride. The recommended safe maximum oral dose in now $0.8 \mathrm{mg} / \mathrm{kg} /$ day $^{28-30}$ We used rectal cisapride, the bioavailability of which is around $40 \%$ of that of an oral dose. ${ }^{31}$ We therefore expect $2 \mathrm{mg} / \mathrm{kg} /$ day to be a safe maximum rectal dose. Cisapride should not be used with erythromycin, clarithromycin, fluconazole, itraconazole, ketoconazole or miconazole, because these agents inhibit the metabolic inactivation of cisapride.

We consider that a study comparing erythromycin with cisapride in postoperative neonates might give us further information, and we are keen to establish if continued management with cisapride significantly shortens hospital stay. Furthermore, the possible benefit of an earlier introduction of prokinetic agents in the postoperative period might be addressed.

1 Briones ER, Iber FL. Liver and biliary tract changes and njury associated with total parenteral nutrition: pathogenesis and prevention. F Am Coll Nutr 1995;14:219-28.

2 Van Nueten JM, Schuurkes JA. Development of a new gastrointestinal prokinetic; pharmacology of cisapride. $\mathcal{F}$ Pharmacol Belgique 1991;46:17-22.

3 Baeyens R, Reyntjens A, Verlinden M. Cisapride accelerates gastric emptying and mouth-to-caecum transit of a barium meal. Eur 7 Clin Pharmacol 1984;27:315-18.

4 Van Rooy F, Creve U, Verlinden M, Hubens A. Effect of cisapride on the post-cholecystectomy upper gastrointestinal transit time. Int $\mathcal{F}$ Clin Pharmacol Ther Toxicol 1988;26:2658.

5 Boghaert A, Haesaert G, Mourisse P, Verlinden M. Placebo-controlled trial of cisapride in postoperative ileus. Acta Anaesthesiol Belgica 1987;38:95-9.

6 Verlinden M, Michiels G, Boghaert A, de Coster M, Dehertog P. Treatment of postoperative gastrointestinal atony. $\mathrm{Br}$ F Surg 1987;74:614-17.

7 Rode H, Stunden RJ, Millar AJ, et al. Esophageal pH assessment of gastroesophageal reflux in 18 patients and the effect of two prokinetic agents: cisapride and metoclopramide. F Pediatr Surg 1987;22:931-4.

8 Hyman PE, McDiarmid SV, Napolitano J, Abrams CE, Tomomasa T. Antroduodenal motility in children with chronic intestinal pseudo-obstruction. $f$ Pediatr 1988;112:899-905.

9 Mearin F, Malagelada JR. Gastroparesis and dyspepsia in patients with diabetes mellitus. Eur F Gastroenterol Hepatol $1995 ; 7: 717-23$ 
10 Longo WE, Vernava AM III. Prokinetic agents for lower gastrointestinal motility disorders. Dis Colon Rectum 1993;36:696-708.

11 Cohen NP, Booth IW, Parashar K, Corkery JJ. Successful management of idiopathic intestinal pseudo-obstruction with cisapride. F Pediatr Surg 1988;23:229-30.

12 Puntis JW, Booth IW, Buick R. Cisapride in neonatal short gut. Lancet 1986;ii: $108-9$

T, Hyman PE, Itoh K, Hsu JY, Koizumi T, Itoh $\mathrm{Z}$, et al. Gastroduodenal motility in neonates: response to human milk compared with cow's milk formula. Pediatrics 1987;80:434-8.

14 Coombs RC, Buick RG, Gornall PG, Corkery JJ, Booth IW. Intestinal malrotation: the role of small intestinal dysmotility in the cause of persistent symptoms. 7 Pediatr Surg 1991;26:553-6.

15 Peeters TL, Depoortere I. Motilin receptor: a model for development of prokinetics. Dig Dis Sci 1994;39:76S-8S.

16 Armstrong DN, Ballantyne GH, Modlin IM. Erythromycin Armstrong DN, Ballantyne GH, Modlin IM. Erythromycin stimulates ileal motility by activation of dihydropyridin
sensitive calcium channels. F Surg Res 1992;52:40-6.

17 Jameson JS, Rogers J, Misiewicz JJ, Raimundo AH, Henry MM. Oral or intravenous erythromycin has no effect on human distal colonic motility. Aliment Pharmacol The 1992;6:589-95.

18 Dive A, Miesse C, Galanti L, Jamart J, Evrard P, Gonzalez $\mathrm{M}$, et al. Effect of erythromycin on gastric motility in mechanically ventilated critically ill patients: a doubleblind, randomized, placebo-controlled study. Crit Care Med 1995;23:1356-62.

19 Pilot MA. Macrolides in roles beyond antibiotic therapy. $\mathrm{Br}$ F Surg 1994;81:1423-29.

20 Minocha A, Katragadda R, Rahal PS, Ries A. Erythromycin shortens orocaecal transit time in diabetic male subjects: a double-blind placebo-controlled study. Aliment Pharmacol Ther 1995;9:529-33.
21 Verne GN, Eaker EY, Hardy E, Sninsky CA. Effect of octreotide and erythromycin on idiopathic and scleroderma1995;40:892-901.

22 Di Lorenzo C, Flores AF, Tomomasa T, Hyman PE. Effect of erythromycin on antroduodenal motility in children with chronic functional gastrointestinal symptoms. Dig Dis Sci 1994;39:1399-404.

23 Kubota M, Nakamura T, Motokura T, Mori S, Nishida A. Erythromycin improves gastrointestinal motility in extremely low birthweight infants. Acta Paediatrica faponica 1994;36:198-201.

24 Tomomasa T, Miyazaki M, Koizumi T, Kuroume T. Erythromycin increases gastric antral motility in human premature infants. Biol Neonate 1993;63:349-52.

25 Simkiss DE, Adams IP, Myrdal U, Booth IW. Erythromycin in neonatal postoperative intestinal dysmotility. Arch Dis in neonatal 1994;71:F128-9.

26 Bonacini M, Quiason S, Reynolds M, Gaddis M, Pemberton B, Smith O. Effect of intravenous erythromycin on postoperative ileus. Am f Gastroenterol 1993;88:208-11.

postoperative ileus. Am f Gastroenterol $1993 ; 88: 208-11$.
27 Hyman PE, Abrams CE, Dubois A. Gastric emptying in infants: response to metoclopramide depends on the underlying condition. 7 Pediatr Gastroenterol Nut $1988 ; 7: 181-4$

28 Lewin MB, Bryant RM, Fenrich AL, Grifka RG. Cisapride induced long QT interval. F Pediatr 1996;128:279-81.

29 Bedu A, Lupoglazoff JM, Faure C, et al. Cisaopride high dosage and long QT interval. F Pediatr 1997;130:164.

30 Hanson R, Browne G, Fasher B, et al. Cisapride induced prolonged QT interval: too much of a good thing. F Pediatr 1996;130:164-5.

31 Hedner T, Hedner J, Gelin-Friberg A, et al. Comparative bioavailability of a cisapride suppository and tablet formulation in healthy volunteers. Eur 7 Clin Pharmacol 1990;38:629-31. 